\title{
Fractography Analysis of Monolithic Epoxy with Tailored Topography
}

\section{Rasheed Atif, Fawad Inam}

Department of Mechanical and Construction Engineering, Faculty of Engineering and Environment, Northumbria University, Newcastle upon Tyne, UK

Email: fawad.inam@northumbria.ac.uk

How to cite this paper: Atif, R. and Inam, F. (2016) Fractography Analysis of Monolithic Epoxy with Tailored Topography. World Journal of Engineering and Technology, 4, 517-527.

http://dx.doi.org/10.4236/wjet.2016.44051

Received: August 30, 2016

Accepted: October 11, 2016

Published: October 14, 2016

Copyright (c) 2016 by authors and Scientific Research Publishing Inc. This work is licensed under the Creative Commons Attribution International License (CC BY 4.0).

http://creativecommons.org/licenses/by/4.0/ (c) (i) Open Access

\begin{abstract}
The topographical features of fractured tensile, flexural, $\mathrm{K}_{1 \mathrm{C}}$, and impact specimens of monolithic epoxy have been studied and correlated with mechanical properties and surface features of samples before fracture. The topographical features studied include waviness $\left(W_{a}\right)$, roughness average $\left(R_{a}\right)$, root mean square value $\left(R_{q}\right)$, and maximum roughness height $\left(\mathrm{R}_{\max }\right.$ or $\left.\mathrm{R}_{\mathrm{z}}\right)$. As surface notches generate triaxial state of stress, therefore, the crack propagation is precipitated resulting in catastrophic failure. Although surfaces can be examined before fracture for any deleterious topographical elements, however, fractured surfaces can reveal finer details about the topography. It is because, as discussed in this article, surfaces with specific topography produce fracture patterns of peculiar aesthetics, and if delved deeper, they can further be used to estimate about the topography of surfaces before fracture. In addition, treating the samples with surfaces of specific topography can help improve the mechanical properties of monolithic epoxy.
\end{abstract}

\section{Keywords}

Fractography, Topography, Monolithic Epoxy, Fracture Toughness, Mechanical Properties

\section{Introduction}

The tribological conservation of technical polymers, such as thermosetting epoxy, is getting increasing interest to use them in various engineering applications [1]-[5]. To grasp the science related to fracture mechanics and tribology, it is of prime significance to investigate the correlations between topography and bulk features [6]. To enhance the wear resistance of monolithic thermosetting and thermoplastic polymers, surface coatings are employed. It is due to the thickening of crystallites in following deposition 
occludes the fissures and offers the choice to tune the topography in accordance with the service/design needs [7]-[10]. Some coating methods are electrochemical/galvanic deposition and thermal and plasma spraying that produce thick coatings with elevated load bear [11].

The influence of topographical features is momentous both at micro and macro level [12] [13]. For example, Karger-Kocsis et al. [14] have rightly stated that hairy and hierarchical reinforcements have high surface area. In addition, polymers do capillary wetting of the fillers that can significantly improve the interfacial interactions and result in a concomitant enhancement in the mechanical properties. In addition, various attributes of the polymers can be studied from the fractography analysis of the samples [15]. The topography also becomes very important when the polymers are applied in tribological applications [16]. It is because the cracks in most of the cases originate from the surfaces [17]. The topography plays a crucial part especially in the presence of surface notches as they generate triaxial state of stress in the presence of which the polymers show a marked degradation in mechanical properties, especially when the polymers are thermosetting such as epoxy. Although micro- and nano-scale topography of polymers and polymer nanocomposites have been discussed in detail, however, the influence of macro-topography on mechanical properties of polymers has been overlooked, especially to correlate the fracture patterns with the topography of samples before fracture takes place.

In current work, monolithic epoxy was treated with abrasive papers to change their topography to correlate with mechanical properties and fracture patterns. The topographical features were studied using an Infinite Focus (G4) Alicona optical microscope. The working principle of Alicona optical microscope is focus-follow technique which is a non-contact method. Non-contact methods are getting growingly famous to determine topography, usually for surfaces that may undergo damage by contact methods [18] [19]. The results achieved are alike to that of stylus methods and can use similar parameter nomenclature. Some non-contact methods can determine topography straightforwardly and briskly and can potentially be employed on the machining instruments. The non-contact techniques have some limiting factors. For instance, in surfaces with high slope, an inadequate power of light enters into the detector and the focus lens starts to track falsely. Additionally, when the impure surfaces are investigated, the impurity is considered as topography as there is no extraneous force to abolish the impurities from the surface [20]. It was observed that mechanical properties of monolithic epoxy are significantly depended upon the topographical features. In addition, the topography significantly influences the fracture patterns of the samples.

\section{Experimental Section}

\subsection{Materials}

Bisphenol A-epichlorohydrin based epoxy (density $\sim 1.3 \mathrm{~g} / \mathrm{cm}^{3}$ ) and dimethylbenzylamineisophoronediamine based low viscosity fast curing hardener with (density $\sim 1.1$ $\mathrm{g} / \mathrm{cm}^{3}$ ) were employed and purchased from Polyfibre, UK. The mixing ratio of hardener: epoxy was 1:2. 


\subsection{Samples Production}

The hardener and epoxy were degassed for $1 \mathrm{~h}$ in separate beakers. The hardener and epoxy were mixed by tip sonicator of $750 \mathrm{~W}$ power and $250 \mathrm{kHz}$ frequency with $5 \mathrm{~s}$ break, $10 \mathrm{~s}$ vibration, and 70\% power (Vibra-cell model VC 750, USA). Then, vacuum degassing was repeated for $15 \mathrm{~min}$. The resin mixture was cast into silicone molds and cured for $6 \mathrm{~h}$ at room temperature and then post-cured at $150^{\circ} \mathrm{C}$ overnight. The bottom and top surfaces of each specimen were processed with abrasive papers on rotating wheels at $150 \mathrm{rpm}$ for $1 \mathrm{~min}$.

\subsection{Characterization}

TAn Infinite focus Alicona G4 optical microscope was employed for microscopy and to measure topography. The working principle of the microscope is focus-follow method which is a non-contact method. ASTM Standard D792 (Equations (1) and (2)) was used to measure densification. The densities of water, hardener, and epoxy were 0.9975, 1.1, and $1.3 \mathrm{~g} / \mathrm{cm}^{3}$, respectively. Vickers microhardness was measured using Buehler Micromet II hardness tester (200 g, $10 \mathrm{~s}$ ). The schematics of mechanical test specimens are shown in Figure 1. Universal Testing Machine (Instron Model 3382) was used to conduct tensile test (ASTM D638, $4 \mathrm{~mm}$ thickness, Type-V geometry, $0.5 \mathrm{~mm} / \mathrm{min}$ ), three-point bending test (ASTM D790, $3 \times 12.7 \times 48 \mathrm{~mm}, 1.0 \mathrm{~mm} / \mathrm{min}$ ), and mode-I fracture toughness test (ASTM D5045, $36 \times 6 \times 3 \mathrm{~mm}$, crack length $3 \mathrm{~mm}, 0.5 \mathrm{~mm} / \mathrm{min}$, Equations (3)-(5)). ASTM standard D 6110 was used to measure Charpy impact toughness (specimen dimensions $64 \times 12.7 \times 3.2 \mathrm{~mm}$ with V-notch of $45^{\circ}, 2.5 \mathrm{~mm}$

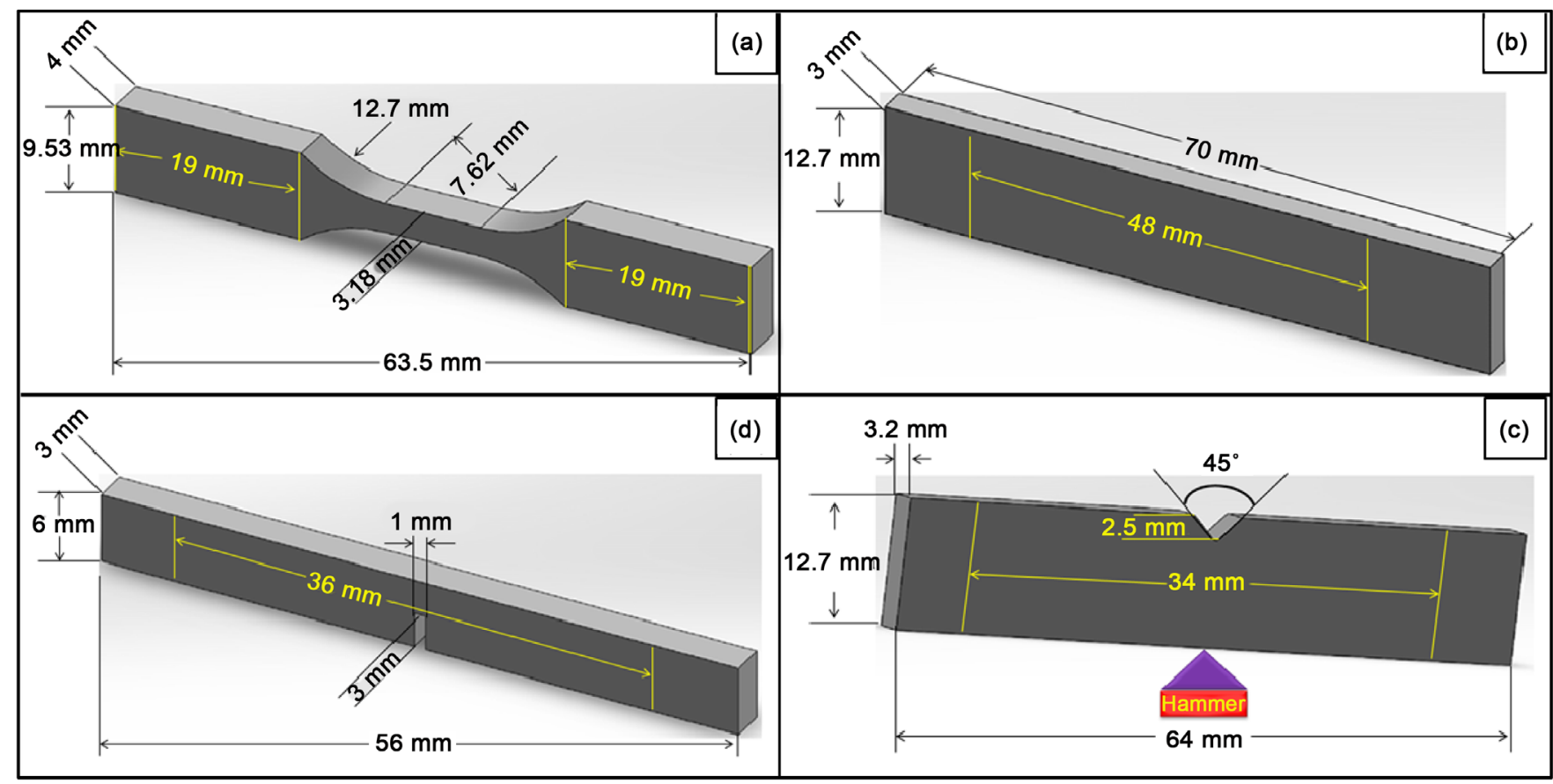

Figure 1. Schematics of mechanical test specimens: (a) tensile; (b) three point bend; (c) Charpy impact toughness; and (d) fracture toughness $\left(\mathrm{K}_{1 \mathrm{C}}\right)$. 
depth and $0.25 \mathrm{~mm}$ tip of radius) using Equation (6). The weight of impactor head was $400 \mathrm{~g}$ and length of impactor arm was $0.4 \mathrm{~m}$. SEM FEI Quanta 200 was used to study the fractured surfaces of tensile samples to investigate the fracture patterns in the specimens. The fractured surfaces were trimmed from the samples and gold layer was employed using SC500A Emscope sputter coater.

$$
\begin{gathered}
\text { Experimental density }=\frac{\text { Weight in Air }}{\text { Weight in Air }- \text { Weight in Water }} \times \text { Density of water } \\
\text { Densification }(\%)=\frac{\text { Experimental Density }}{\text { Theoretical Density }} \times 100 \\
\qquad(a / w)=\frac{P_{\text {max }} f\left(\frac{a}{w}\right)}{B W^{1 / 2}} \\
{\left[\left(2+\frac{a}{w}\right)\left\{0.0866+4.64\left(\frac{a}{w}\right)-13.32\left(\frac{a}{w}\right)^{2}+14.72\left(\frac{a}{w}\right)^{3}-5.6\left(\frac{a}{w}\right)^{4}\right\}\right]} \\
\text { Impact toughness }=\frac{m g h(\cos \beta-\cos \alpha)}{w t} \\
\left.G_{1 c}=\frac{K_{1 c}^{2}\left(1-v^{2}\right)}{E}\right)^{3 / 2}
\end{gathered}
$$

\section{Results and Discussion}

\begin{tabular}{|c|c|c|c|c|c|c|}
\hline Sr. & Properties & As-cast & $\mathrm{VC}$ & $1200 \mathrm{P}$ & $320 \mathrm{P}$ & $60 \mathrm{P}$ \\
\hline 1 & Densification (\%) & $99.3 \pm 0.37$ & $99.1 \pm 0.31$ & $99.2 \pm 0.34$ & $99.4 \pm 0.29$ & $99.3 \pm 0.36$ \\
\hline 2 & Microhardness (HV) & $278.2 \pm 15.2$ & $391.2 \pm 10.2$ & $437.9 \pm 11.8$ & $335 \pm 18.6$ & $298 \pm 21.7$ \\
\hline 3 & Young's modulus (MPa) & $748.6 \pm 24.7$ & $776.1 \pm 21.3$ & $781.6 \pm 29.4$ & $741.9 \pm 33.4$ & $726.9 \pm 36.4$ \\
\hline 4 & UTS (MPa) & $50.2 \pm 2.7$ & $51.5 \pm 2.7$ & $54.7 \pm 2.3$ & $49.6 \pm 2.9$ & $47.3 \pm 3.1$ \\
\hline 5 & Tensile strain (\%) & $7.2 \pm 1.0$ & $7.4 \pm 1.1$ & $8.5 \pm 1.3$ & $9.1 \pm 1.7$ & $12.3 \pm 2.3$ \\
\hline 6 & Flex. Modulus (MPa) & $729 \pm 38.3$ & $787.1 \pm 25.3$ & $797.3 \pm 30.5$ & $762.9 \pm 33.5$ & $652.9 \pm 42.6$ \\
\hline 7 & Flex. Strength (MPa) & $68.7 \pm 6.9$ & $71.5 \pm 3.8$ & $79.9 \pm 2.9$ & $65.6 \pm 4.6$ & $63.6 \pm 8.3$ \\
\hline 8 & Flex. Strain (\%) & $5.8 \pm 0.06$ & $5.8 \pm 0.29$ & $5.9 \pm 0.31$ & $6.2 \pm 0.49$ & $6.9 \pm 0.4$ \\
\hline 9 & $\mathrm{~K} 1 \mathrm{C}\left(\mathrm{MPa} \cdot \mathrm{m}^{1 / 2}\right)$ & $1.02 \pm 0.1$ & $1.04 \pm 0.15$ & $1.04 \pm 0.05$ & $1.03 \pm 0.1$ & $1.02 \pm 0.1$ \\
\hline 10 & $\mathrm{G} 1 \mathrm{C}\left(\mathrm{J} / \mathrm{m}^{2}\right)$ & $341.5 \pm 51.5$ & $546.6 \pm 42.3$ & $620.5 \pm 47.9$ & $684.7 \pm 62.8$ & $759.6 \pm 69.8$ \\
\hline 11 & Charpy $\left(\mathrm{kJ} / \mathrm{m}^{2}\right)$ & $1.11 \pm 0.15$ & $1.15 \pm 0.1$ & $1.17 \pm 0.09$ & $1.12 \pm 0.12$ & $1.01 \pm 0.2$ \\
\hline
\end{tabular}

The densification values and mechanical properties are summarized in Table 1. The variation in density values may be either yielded by treating with abrasive papers or the specimens had different density before the processing with the abrasive papers as casting is not as reproducible as latex method [21]. The topography influenced mechanical

Table 1. Mechanical properties of monolithic epoxy with tailored topography. 
performance of epoxy samples. The microhardness of specimens (as-cast) is $277 \mathrm{HV}$. When processed with velvet cloth (VC), the hardness enhanced to $392 \mathrm{HV}$ (40\% increase). When processed with $1200 \mathrm{P}$, hardness enhanced to $439 \mathrm{HV}$ (57\% increase). This improvement in hardness values can be related to the straightening of surfaces. High roughness values were recorded in samples (as-cast). When specimens have fluted surface, the edge of indenter may not hit completely on edge of the sample. When the indenter comes in contact with the flat surface, hindrance is presented by the surface beneath and high hardness was recorded. On the other hand, when indenter comes in contact with the corners, decreased hindrance is presented by the corners, and hence, the hardness values decreased. In specimens processed with VC and $1200 \mathrm{P}$, smoothness enhanced or sharp sections were truncated. Hence, an increment in hardness was recorded. The hardness degraded in specimens processed with $320 \mathrm{P}$ and $60 \mathrm{P}$ which indicates that indenter bears low hindrance due to fluted topography.

The stiffness improved from $749 \mathrm{MPa}$ to $776 \mathrm{MPa}$ (4.1\% increase) when samples were processed with VC. The stiffness of epoxy processed with $1200 \mathrm{P}$ also enhanced to $782 \mathrm{MPa}$ (4.9\% increase). Nevertheless, the stiffness of samples processed with $320 \mathrm{P}$ degraded to $742 \mathrm{MPa}$ (1\% decrease). The maximum degradation in stiffness was recorded when the specimens were processed with $60 \mathrm{P}$ and degraded to $727 \mathrm{MPa}$ (2.9\% decrease). The results indicate that stiffness can be improved by treating the epoxy with $\mathrm{VC}$ and $1200 \mathrm{P}$ and degraded by treating the samples with $320 \mathrm{P}$ and $60 \mathrm{P}$. The UTS of samples treated with VC changed from 49.8 MPa to $51.9 \mathrm{MPa}$ (2.9\% increase). The maximum enhancement in UTS was recorded when samples were processed with 1200 $\mathrm{P}$ and UTS became $55 \mathrm{MPa}$ (3.9\% increase). The UTS of samples processed with $60 \mathrm{P}$ degraded to $48.9 \mathrm{MPa}$ (1.9\% decrease). When processed with $60 \mathrm{P}$, the UTS degraded to 46.8 $\mathrm{MPa}$ (4.9\% decrease). The improvement in stiffness and UTS with VC and $1200 \mathrm{P}$ can be because of the straightening of surfaces as samples (as-cast) had roughness of $\pm 14 \mu \mathrm{m}$. In contrary, the roughness of samples processed with VC changed between \pm 4 $\mu \mathrm{m}$ while that of $1200 \mathrm{P}$ fluctuated between $\pm 3 \mu \mathrm{m}$. Hence, modulus and strength can be enhanced by treating the samples with VC and $1200 \mathrm{P}$. On the other hand, the roughness of samples processed with $320 \mathrm{P}$ abrasive paper fluctuated between $\pm 20 \mu \mathrm{m}$ while roughness of $60 \mathrm{P}$ fluctuated between $\pm 30 \mu \mathrm{m}$. Therefore, roughness above \pm 20 $\mu \mathrm{m}$ shows deleterious impact on strength and stiffness of samples. The tensile strain increased with coarser topography which can be because of decreased strength and stiffness values. The tensile strain showed no marked variation with VC and marginally enhanced in $1200 \mathrm{P}$. Hence, improved tensile features can be obtained when specimens were processed with VC and $1200 \mathrm{P}$. Similar results were recorded for flexural properties.

It was observed that $\mathrm{K}_{1 \mathrm{C}}$ values were unchanged. One reason can be the direction of roughness. It was observed that roughness perpendicular to loading direction does not significantly change the mechanical performance. The results indicate that standard deviation is disparate for different specimens. It may be attributed to the notch tip that was manually honed that does not replicate length and curvature of notch tip. In addition, 
the distribution, size, and volume fraction of porosity can be an additional aspect that can affect the mechanical performance. The trend indicates that $\mathrm{G}_{1 \mathrm{C}}$ improves with the coarsening of roughness. Nevertheless, as topography did not record any marked impact on $\mathrm{K}_{1 \mathrm{C}}$, we believe that this increase in $\mathrm{G}_{1 \mathrm{C}}$ is not arising from the topography. In calculating $G_{1 C}, K_{-} 1 C^{\wedge} 2$ is divided by stiffness. As stiffness degraded with coarse topographical features, hence the increment in $\mathrm{G}_{1 \mathrm{C}}$ is probably coming from degraded stiffness. No major difference was recorded in fracture toughness results. Nevertheless, processing of specimens with abrasive papers recorded a marked influence on Charpy impact results. The change in flexural stress-strain is presented in Figure 2. It is worthy to mention that all the samples did not show the same trend as presented in Figure 2. The average results should be taken from Figure 2. As shown in Figure 2, the epoxy (as-cast) recorded a brittle fracture. It can be attributed to the stiffness associated with the monolithic epoxy. In addition, existence of any porosity and notches at surface may also contribute toward brittle fracture. When specimens were processed with VC and $1200 \mathrm{P}$, flexural modulus and flexural strength were enhanced. Nevertheless, processing with $60 \mathrm{P}$ and $320 \mathrm{P}$ had deleterious influence on flexural features.

The fractography surfaces of specimens are presented in Figure 3 and Figure 4 . The as-cast epoxy showed straight bamboo-like fracture pattern indicating the occurrence of typical epoxy brittle fracture. It is because crack bridging mechanisms are unavailable in monolithic epoxy [22] [23]. However, with the treatment with abrasive papers, a shift in crack propagation and fracture pattern was observed. The fracture became coarser when the samples were processed with VC and $1200 \mathrm{P}$ while trenches and straight and flat fracture patterns were recorded when the specimens were processed

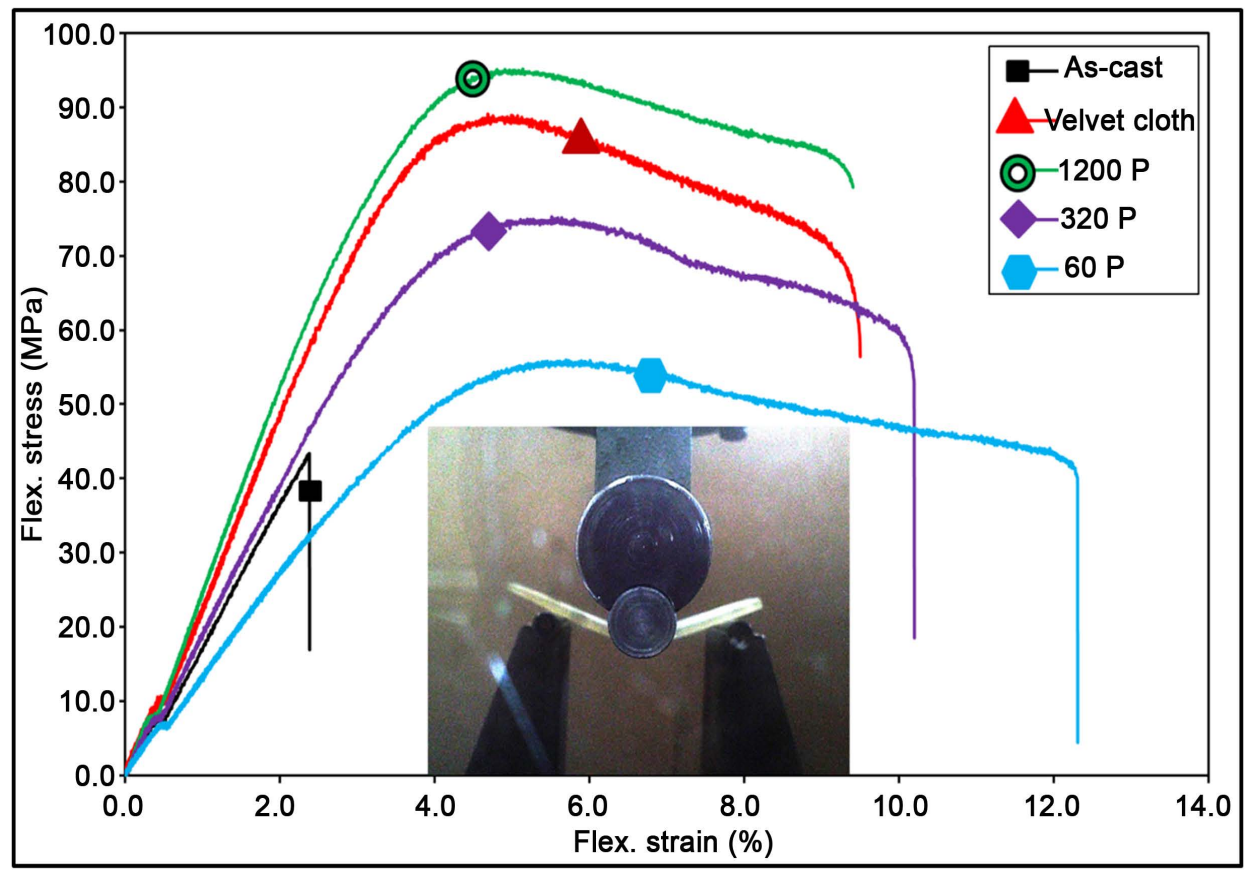

Figure 2. Flex. Stress vs Flex. Strain curves of monolithic epoxy samples [24]. 


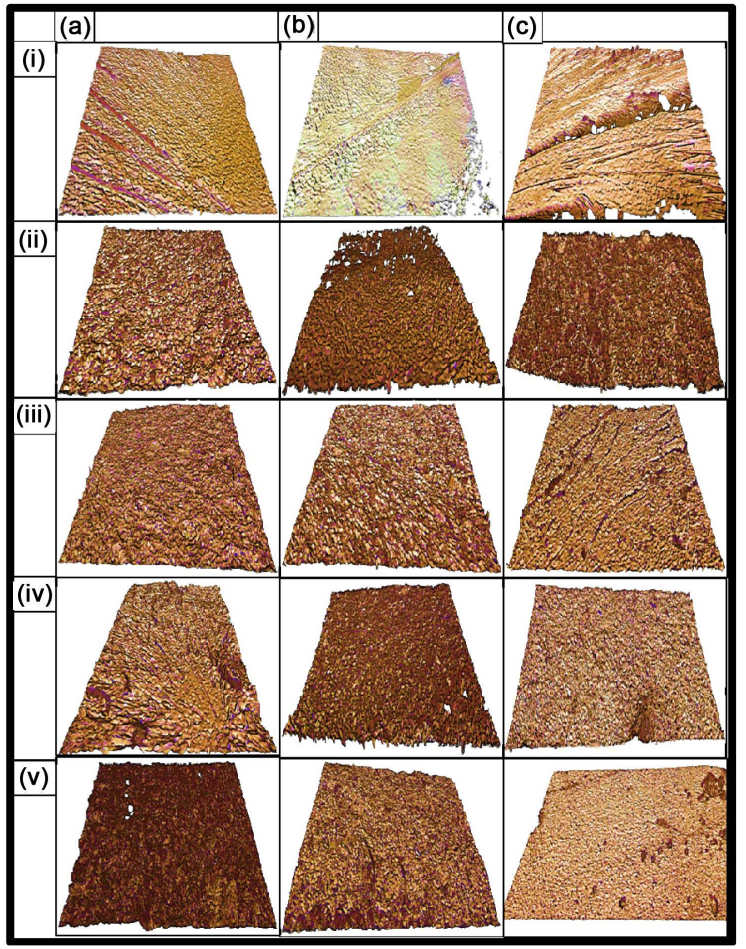

Figure 3. Fractured surfaces of (a) 3PBT; (b) $\mathrm{K}_{1 \mathrm{C}}$; and (c) Charpy impact test specimens of monolithic epoxy samples. From top to bottom: (i) as-cast, (ii) treated with VC, (iii) $1200 \mathrm{P}$, (iv) $320 \mathrm{P}$, and (v) $60 \mathrm{P}$. The length of bottom edge of each image is $800 \mathrm{~nm}$.
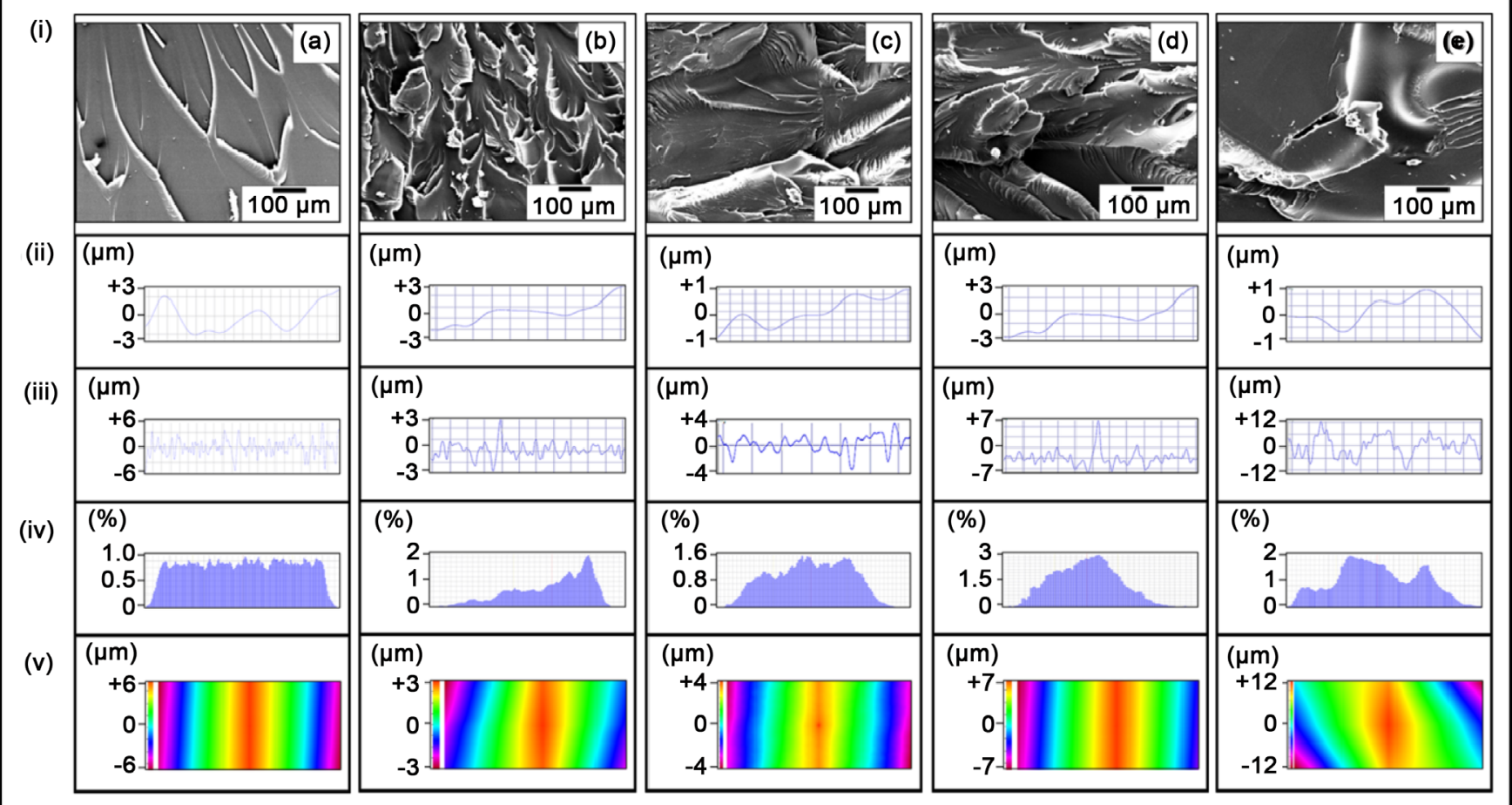

Figure 4. Topographical features of fractured tensile samples: (a) as-cast, processed with: (b) VC; (c) 1200 P; (d) 320 P; and (e) 60 P. From top to bottom: (i) tensile images (ii) waviness, (iii) roughness, (iv) Gaussian distribution, and (v) surface profile. 
with $60 \mathrm{P}$ and $320 \mathrm{P}$. The fracture patterns of $\mathrm{K}_{1 \mathrm{C}}$ specimens differ from those of 3PBT specimens in a way that fracture was originated from the notch tip as the tip generated high levels of stress concentration. Although there were no diversions in crack path in case of as-cast epoxy, however, a bit coarser topography was recorded in samples processed with the abrasive papers. As the displacement rate is relatively low in $\mathrm{K}_{1 \mathrm{C}}$ testing, the surface notches showed a significant impact on the topography of fracture surfaces. However, the influence of surface notches and topographical features on fracture patterns was marginalized in case of Charpy impact testing where the samples were suddenly impacted at the back of the notch by a heavy and pointed hammer. Sheer and straight fracture patterns were observed in Charpy impact specimens and fracture occured right from the notch tip.

The surface waviness (Figure 4(ii)) and Gaussian distribution (Figure 4(iv)) did not show a specific trend of change with the abrasive papers. It can be attributed to the multiple factors affecting the fracture pattern such as size, distribution, and orientation of surface notches. On the contrary to $\mathrm{W}_{\mathrm{a}}$, a specific variation in surface roughness (Figure 4(iii)) was observed. The surface roughness of monolithic epoxy varied between $\pm 6 \mu \mathrm{m}$ with the presence of deep crests and troughs. With the treatment with the $\mathrm{VC}$, the surface roughness changed slightly which became pronounced in samples processed with $1200 \mathrm{P}$. However, in samples processed with $60 \mathrm{P}$ and $320 \mathrm{P}$, deep trenches can be observed in roughness patterns (Figure 4(diii) and Figure 4(eiii)) that may be attributed to the presence of large notches. The trenches can also be observed in the surface profiles (Figure 4(dv) and Figure 4(ev)).

The topographical features are summarized in Figure 5. The $R_{z}$ value of monolithic epoxy (as-cast) is $7.24 \mu \mathrm{m}$. This $\mathrm{R}_{\mathrm{z}}$ comes from the ravines formed due to brittle fracture

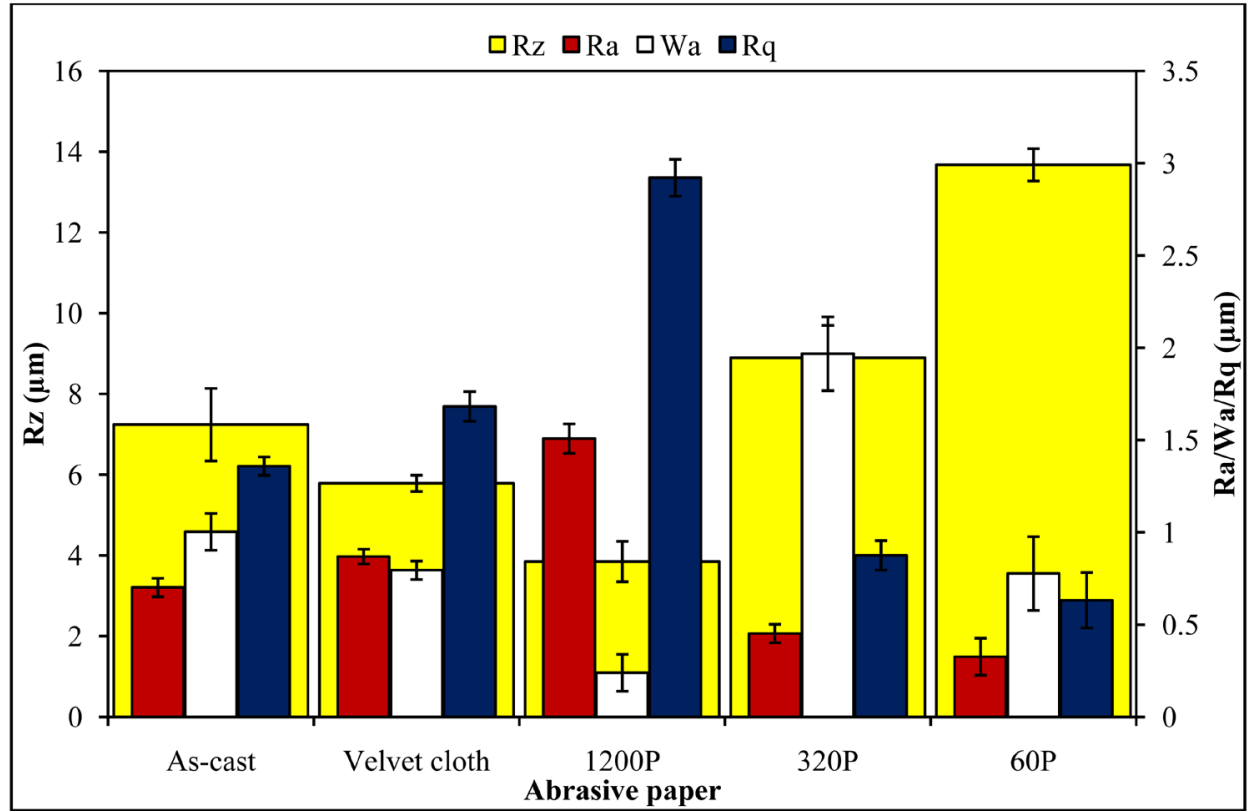

Figure 5. Topographical features of tensile specimens of monolithic epoxy samples. 
in the thermoset. The $\mathrm{R}_{\mathrm{z}}$ values decreased when the specimens were processed with VC and $1200 \mathrm{P}$ and increased when treated with $60 \mathrm{P}$ and $320 \mathrm{P}$ abrasive papers. As ravines were partially removed with $1200 \mathrm{P}$ and VC, therefore, a reduction in $\mathrm{R}_{\mathrm{z}}$ indicates that severe surface notches present in the as-cast samples were removed by the treatment with VC and $1200 \mathrm{P}$ abrasive paper. In addition, an increase in mechanical properties when processed with $\mathrm{VC}$ and $1200 \mathrm{P}$ further validates the removal of deep notches. On the contrary, in samples processed with $320 \mathrm{P}$ and $60 \mathrm{P}$ abrasive papers, the $\mathrm{R}_{\mathrm{z}}$ values increased and were even higher than those in as-cast monolithic epoxy samples. Therefore, increase in $R_{z}$ values and the presence of craters and trenches indicate that both abrasive papers $320 \mathrm{P}$ and $60 \mathrm{P}$ produced severe surface notches that caused the fracture. A decrease in mechanical properties when treated with $320 \mathrm{P}$ and $60 \mathrm{P}$ abrasive papers further corroborates the presence of severe surface notches which act as stress concentration sites and causes fracture. Therefore, $R_{z}$ of fractured surfaces can be an indicator of the topographical features of the samples. Apart from $R_{z}, R_{a}$ is another important parameter to consider. The decrease in Ra with increasing $R_{z}$ may seem contradicting however can be explained on the basis of observed fractured patterns and surface roughness charts shown in Figure 4. When processed with VC and $1200 \mathrm{P}$ abrasive paper, no crater was formed due to which lower $R_{z}$ value was observed. In addition, cracks were deflected quite sharply resulting in sudden variation in surface roughness thereby increasing the Ra value. On the contrary, when treated with $60 \mathrm{P}$ and $320 \mathrm{P}$ abrasive papers, deep notches were present that caused fracture and increased $R_{z}$ due to crater formation. However, once cracked formed, it could not deflect much and rest of the fractured surface remained flat thereby decreasing the $R_{a}$ value. Therefore, a high value of $R_{a}$ (with low $R_{z}$ value) can be on indicator of smoother samples surfaces. On the other hand, a low value of $R_{a}$ (with high $R_{z}$ value) indicates the presence of deep surface notches. A similar trend was recorded in $\mathrm{R}_{\mathrm{q}}$ values as in $\mathrm{R}_{\mathrm{a}}$ values. However, no specific trend was observed in surface waviness and may not be indicative of topographical features.

\section{Conclusion}

The mechanical performance is a function of topography and also depends on the orientation of topography. The topography of fractured patterns of monolithic epoxy can be used to approximate the topography of samples before fracture. It was recorded that epoxy (as-cast) had roughness that was decreased when processed with VC and $1200 \mathrm{P}$ and enhanced by $60 \mathrm{P}$ and $320 \mathrm{P}$. The highest enhancement in mechanical performance was recorded when specimens were processed with $1200 \mathrm{P}$. A high value of $\mathrm{R}_{a}$ (with low $R_{z}$ value) can be on indicator of smoother samples surfaces. On the other hand, a low value of $R_{a}$ (with high $R_{z}$ value) indicates the presence of deep surface notches. A similar trend was observed in $R_{q}$ values as in $R_{a}$ values. However, no specific trend was observed in surface waviness and may not be indicative of topographical features. The fracture patterns suggest that when the surface notch goes beyond certain severity, brittle fracture occurs. In addition, treating the samples with surfaces of specific topography can help improve the mechanical properties of monolithic epoxy. 


\section{Acknowledgements}

The authors would like to thank the Department of Mechanical and Construction Engineering, Northumbria University, UK for the provision of research facilities, without which the analysis of relevant data was not possible.

\section{References}

[1] Rider, A.N. and Arnott, D.R. (2001) The Influence of Adherend Topography on the Fracture Toughness of Aluminium-Epoxy Adhesive Joints in Humid Environments. The Journal of Adhesion, 75, 203-228. http://dx.doi.org/10.1080/00218460108029601

[2] Schuler, M., Kunzler, T.P., De Wild, M., Sprecher, C.M., Trentin, D., Brunette, D.M., et al. (2009) Fabrication of $\mathrm{TiO}_{2}$-Coated Epoxy Replicas with Identical Dual-Type Surface Topographies Used in Cell Culture Assays. Journal of Biomedical Materials Research Part A, 88, 12-22. http://dx.doi.org/10.1002/jbm.a.31720

[3] Lam, C.K. and Lau, K.T. (2007) Tribological Behavior of Nanoclay/Epoxy Composites. Materials Letters, 61, 3863-3866. http://dx.doi.org/10.1016/j.matlet.2006.12.078

[4] Yu, S., Hu, H., Ma, J. and Yin, J. (2008) Tribological Properties of Epoxy/Rubber Nanocomposites. Tribology International, 41, 1205-1211. http://dx.doi.org/10.1016/j.triboint.2008.03.001

[5] Xia, S., Liu, Y., Pei, F., Zhang, L., Gao, Q., Zou, W., et al. (2015) Identical Steady Tribological Performance of Graphene-Oxide-Strengthened Polyurethane/Epoxy Interpenetrating Polymer Networks Derived from Graphene Nanosheet. Polymer (Guildf), 64, 62-68. http://dx.doi.org/10.1016/j.polymer.2015.03.036

[6] Siegel, R., Hu, E. and Roco, M., Eds. (1999) Nanostructure Science and Technology. A Worldwide Study. Prepared under the Guidance of the IWGN, NSTC. WTEC.

[7] Pan, G., Guo, Q., Ding, J., Zhang, W. and Wang, X. (2010) Tribological Behaviors of Graphite/Epoxy Two-Phase Composite Coatings. Tribology International, 43, 1318-1325. http://dx.doi.org/10.1016/j.triboint.2009.12.068

[8] Brostow, W., Dutta, M. and Rusek, P. (2010) Modified Epoxy Coatings on Mild Steel: Tribology and Surface Energy. European Polymer Journal, 46, 2181-2189.

http://dx.doi.org/10.1016/j.eurpolymj.2010.08.006

[9] Zhang, W.H. and Hsieh, J.H. (2000) Tribological Behavior of TiN and CrN Coatings Sliding against an Epoxy molding Compound. Surface and Coatings Technology, 130, 240-247. http://dx.doi.org/10.1016/S0257-8972(00)00709-X

[10] Chang, L., Zhang, Z., Ye, L. and Friedrich, K. (2007) Tribological Properties of Epoxy Nanocomposites. III. Characteristics of Transfer Films. Wear, 262, 699-706. http://dx.doi.org/10.1016/j.wear.2006.08.002

[11] Lackner, J.M., Waldhauser, W., Ganser, C., Teichert, C., Kot, M. and Major, L. (2014) Mechanisms of Topography Formation of Magnetron-Sputtered Chromium-Based Coatings on Epoxy Polymer Composites. Surface and Coatings Technology, 241, 80-85. http://dx.doi.org/10.1016/j.surfcoat.2013.07.040

[12] Karger-Kocsis, J. and Friedrich, K. (1993) Microstructure-Related Fracture Toughness and Fatigue Crack Growth Behaviour in Toughened, Anhydride-Cured Epoxy Resins. Composites Science and Technology, 48, 263-272. http://dx.doi.org/10.1016/0266-3538(93)90143-5

[13] Padenko, E., Berki, P., Wetzel, B. and Karger-Kocsis, J. (2016) Mechanical and Abrasion Wear Properties of Hydrogenated Nitrile Butadiene Rubber of Identical Hardness Filled with Carbon Black and Silica. Journal of Reinforced Plastics and Composites, 35, 81-91. http://dx.doi.org/10.1177/0731684415614087 
[14] Karger-Kocsis, J., Mahmood, H. and Pegoretti, A. (2015) Recent Advances in Fiber/Matrix Interphase Engineering for Polymer Composites. Progress in Materials Science, 73, 1-43. http://dx.doi.org/10.1016/j.pmatsci.2015.02.003

[15] Romhány, G., Wu, C., Lai, W. and Karger-Kocsis, J. (2016) Fracture Behavior and Damage Development in Self-Reinforced PET Composites Assessed by Located Acoustic Emission and Thermography: Effects of Flame Retardant and Recycled PET. Composites Science and Technology, 132, 76-83. http://dx.doi.org/10.1016/j.compscitech.2016.06.014

[16] Friedrich, K., Schlarb, A.K., Karger-Kocsis, J. and Felhős, D. (2013) Tribology of Polymeric Nanocomposites. Elsevier, Oxford, UK.

[17] Turcsán, T., Mészáros, L., Khumalo, V.M., Thomann, R. and Karger-Kocsis, J. (2014) Fracture Behavior of Boehmite-Filled Polypropylene Block Copolymer Nanocomposites as Assessed by the Essential Work of Fracture Concept. Journal of Applied Polymer Science, 131, 40447. http://dx.doi.org/10.1002/app.40447

[18] Gutjahr, P., Lipowsky, R. and Kierfeld, J. (2010) Semiflexible Polymer Rings on Topographically and Chemically Structured Surfaces. Soft Matter, 6, 5461-5475.

http://dx.doi.org/10.1039/c0sm00381f

[19] Ding, Y., Qi, H.J., Alvine, K.J., Ro, H.W., Ahn, D.U., Lin-Gibson, S., et al. (2010) Stability and Surface Topography Evolution in Nanoimprinted Polymer Patterns under a Thermal Gradient. Macromolecules, 43, 8191-8201. http://dx.doi.org/10.1021/ma1018632

[20] Cotell, C.M., Sprague, J.A. and Smidth, F.A.J., Eds. (1994) ASM Handbook, Vol. 5. Surface Engineering.

[21] Berger, M.A. and McCullough, R.L. (1985) Characterization and Analysis of the Electrical Properties of a Metal-Filled Polymer. Composites Science and Technology, 22, 81-106. http://dx.doi.org/10.1016/0266-3538(85)90078-8

[22] Shokrieh, M.M., Esmkhani, M., Shahverdi, H.R. and Vahedi, F. (2013) Effect of Graphene Nanosheets (GNS) and Graphite Nanoplatelets (GNP) on the Mechanical Properties of Epoxy Nanocomposites. Science of Advanced Materials, 5, 260-266. http://dx.doi.org/10.1166/sam.2013.1453

[23] Atif, R. and Inam, F. (2016) Modeling and Simulation of Graphene Based Polymer Nanocomposites: Advances in the Last Decade. Graphene, 5, 96-142.

[24] Atif, R. and Inam, F. (2016) Influence of Macro-Topography on Damage Tolerance and Fracture Toughness of Monolithic Epoxy for Tribological Applications. World Journal of Engineering and Technology, 4, 335-360. 
Submit or recommend next manuscript to SCIRP and we will provide best service for you:

Accepting pre-submission inquiries through Email, Facebook, LinkedIn, Twitter, etc. A wide selection of journals (inclusive of 9 subjects, more than 200 journals)

Providing 24-hour high-quality service

User-friendly online submission system

Fair and swift peer-review system

Efficient typesetting and proofreading procedure

Display of the result of downloads and visits, as well as the number of cited articles

Maximum dissemination of your research work

Submit your manuscript at: http://papersubmission.scirp.org/

Or contact wjet@scirp.org 